\section{Science and Medicine in Central Africa}

Edited by George J. SNowball. Proceedings of the Central Africa Scientific and Medical Congress held at the College of Further Education, Lusaka. August 1963. Pp. xiii +980 illustrated. Oxford, London etc.: Pergamon Press. 1965. $£ 10$.

This is a handsome and well produced volume, whose weight is a measure of the range and scientific value of the material of which it is composed. It records the proceedings of a scientific congress which must be unique in Africa. This was held in Lusaka in 1963 as the highlight of the Jubilee celebrations of that pleasant and progressive oity: it was a sequel to the first Federal Scientific Conference held in Salisbury, Southern Rhodesia in 1960.

A thoughtful and sobering introduction was given by the Mayor of Lusaka who propounded the thesis that as yet the vast achievements of science have not improved the nature of man while psychology remains an analytical science with little material achievement in the realm of human relationships. This was followed by two full congressional sessions dealing respectively with agricultural education and the problems of blindness in Northern Rhodesia (now Zambia). The importance of the latter subject is starkly emphasised by the blindness rate which is probably the highest in the world, being 500 per 100,000 of the population; European rates are between 40-60 per 100,000. It appears that Vitamin A deficiency renders the eyes of children especially susceptible to the effects of measles and to the indigenous remedies applied.

The section on Physical Sciences contains a truly remarkable collection of papers, most of which are beyond the understanding, though not the appreciation of a medical reviewer. Building design, icing on an aeroplane, the geology of Central Africa, the subsoil water reserves of Northen Rhodesia and the use of the poldering type of irrigation are all subjects of great local interest. Sanitary systems best adapted to local conditions and habits are examined, after which the Section turned to the physical structure of the Kalahari sands, and to the measurement and control of the dust hazard in the Copper Belt mines. A highly technical paper on roller bearing engineering is followed by a fascinating account of the protection of the insulation of telephone cables by the maintenance of a flow of dry compressed air wihin their sheaths. A progressive area has already linked a number of towns with an S.T.D. telephone system.

The Biological Sciences Section discussed the variations in the bird population caused by deforestation and the construction of numerous dams, the evolution of Termite mounds, the chemical structure of the exoskeletion of certain arthropods, an analysis of the larval forms of trematodea and a study of dragonflies. The discovery of small, blind, freshwater shrimps was an unexpected result of boring into the deeply situated water-bearing clefts of the dolomite rocks on which Lusaka is built. A study of microfossils in the coalfields of Eastern Nigeria precedes a paper on fish production in Northen Rhodesia. Farm planning and the physical use of land, the need for sulphur and potassium in Northern Rhodesian soils and experiments on grass management are all papers of immediate and practical value to farmers.

The Social Sciences Section includes papers on archeology, advances in housing, adult education, urbanisation of the African population, literacy training, crime among women and a broad-minded examination of the economic development of Central Africa.

While the reviewer can only record his interest in the preceding sections, he can state with assurance that the papers which comprise the last section, on Medical Sciences, in their range and quality fully justify the publication of this volume. An examination of serum enzyme levels in Africans and of glucose 6-phosphate dehydrogenase is followed by a discussion on accidents and an important paper on leprosy in Northern Rhodesia. The incidence of one patient per 100 of the African population is reported as being the highest in the world. In Barotseland, the incidence may even be as high as four per 100 : the disease is described as ancient and increasing Pneumoconiosis appears to have been eliminated from the copper mines. A study of eleatrocardiographic changes in kwashiorkor shows that these may be permanent and differ somewhat from the anomalies seen in pellagra. Valuable papers on schistosomiasis show that in a lakeside community in Tanganyika the overall incidence of ancylostomiasis is $82 \%$, of infection with $S$. haematobium $26.2 \%$ and of $S$. mansoni $36.5 \%$, while $3.7 \%$ of men and $5.9 \%$ of women have haemoglobin concentrations below $8 \mathrm{gm} . \%$. Other papers describe staphylococcal septicaemia in Southern Rhodesia and surgical problems in Lusaka. Three surgeons from England have contributed valuable papers, Rodney Smith on hepatic resection, Norman Tanner on carcinoma of the stomach and Laurence Abel on carcinoma of the colon and rectum. A. J. P. Graham describes the use of the heart-lung machine in open cardiac surgery, but the large staff required must restrict the use of this technique to a feug exceptionally well-equipped centres. E. Kreft gives a highly topical article on the treatment of chronic osteomyelitis. A measure of the industrial advance of the Rhodesias is given by W. V. James who state that two thirds of the hand injuries treated among Africans in Buluwayo were due to industrial accidents, and 1,000 such injuries were treated in 1962 alone The final paper printed in full, by D. H. Thomson of the Medical Research Centre, Buluwayo, describes the use of the goat as a subject for experimental surgery.

This was clearly a most stimulating congress, and its proceedings, worthily recorded in this volume, deserve a place in every reference library. Federation fostered research over a wide area and on a scale which individual countries of Central Africa are unlikely to be able to maintain: the reader of this volume cannot help reflecting sadly on the destructive influence of political ambition and narrow nationalism.

\section{Exfoliative Cytology in Gynaecological Practice}

Erica G. Wachtel. Pp. xiii +203 , illustrated. London: Butterworths. 1964. 45s.

The subject of exfoliative cytology of the female genital tract has gained an increasingly more prominent place in the practice of gynaecology and pathology in recent years. Whilst endocrine cytology is becoming recognised as a useful additional diagnostic tool, it is in the detection of malignancy of the female genital tract that cytological techniques have come to the fore as an almost indispensable aid to clinical diagnosis. Diagnostic cytology owes its success to the painstaking work of a few pioneers in this field, among whom Dr. Erica Wachtel is a leading authority in this country. As a result of their work the mass 
screening of well women for the deteotion of early malignant and pre-malignant conditions of the cervix has recently become accepted as a valid measure of preventive medicine in this country and a massive training programme for technicians was initiated. The need for textbooks on the subjeot became very apparent and few people can be better qualified to fill this gap than the author of this book.

This textbook was first published in 1964. The author states that the text is meant as an introduction to the subject to those who wish to acquaint themselves with the techniques and with the basic principles involved; it does not claim to be a reference book. As an introduotion, it is a remarkably lucid statement. The first two chapters deal with techniques of smear taking and with staining techniques. The three following chapters deal with normal smear patterns and give an outline of endocrine cytology. The author's wide experience is reflected here in the critical view of the applications as well as of the limitations of the method. The chapter on the diagnosis of malignancy is relatively brief but extremely cogent. A comprehensive bibliography, which is referred to in the text, is included at the end of the book. A large number of photomicrographs illustrate the text, but these are not all of a uniformly high standard.

This short book sets out very adequately guide lines for practitioners in the field; it offers an excellent, albeit brief, presentation of the subject and can therefore be strongly recommended to gynaecologists and to general medical readers.

\section{An Outline and Atlas of Gynaecological Cytodiagnosis}

By H. D. Smolka, and H.-J. Soost. Pp. 208, illustrated. London: Edward Arnold. 1965. £6.

This textbook is a welcome addition to the very limited number of authoritative reference books which exist on a subject which is rapidly gaining in interest and topicality in this country.

The book amply fulfils the dual purpose implied in its title. As an atlas it contains a large number of illustrations, many of them in colour, which are of an extremely high standard throughout. The presentation of the text in the chapters dealing with endocrine cytology reveals at all times the critical judgment of the authors. "The limitations of cytological hormone diagniosis must be recognised. They are mainly due to the limited manner in which the vaginal epithelium can react in response to different hormonal stimuli." This statement may be selfevident, but cannot be overemphasised. An equally cautious approach is reflected in the rather brief section of the book which deals with the diagnosis of malignancy. This reviewer likes the nomenclature chosen by the authors who use the term "atypical cells" as meaning cells suspected of malignancy; "such cells may originate from a malignant process, from a carcinoma in situ or from a dysplastic area" and "their presence generally only allows a probable diagnosis and never a definite diagnosis of cancer" (p. 142). Two points appear to be implied in these passages - first, the recognition of the subjective element in the diagnosis of malignancy of cells-a point which is well worth emphasising. This approach could be extended to the recognition of the subjective element in the histological diagnosis of these lesions. The authors however set up histological criteria as absolute arbiters; secondly, a qualitative distinction appears to have been made between a malignant process and carcinoma in situ. It is therefore disappointing to find that the whole subject of carcinoma in situ, its relationship to the dysplasias on one hand, and to invasive growth on the other is treated so briefly as to be almost perfunctory. The confusion which arises in the text when the terms "atypical" and "abnormal" cells are used sometimes synonymously, and at other times as implying different grades of a process is a minor defect. In spite of these objections it must be emphasised that this book offers an excellent and detached presentation of its main subject. The quality of the illustrations is outstanding and the book can be strongly recommended to specialists as well as to the more casual reader. The Application of Neuroleptanalgesia in Anaeshetic
and Other Practice

Edited by N. W. Shephard. Proceedings of the 1st. British Symposium sponsored by Jansen Pharmaceuticals Division of Ortho Pharmaceuticals Ltd. Edinburgh. June 1964. Pp. ix +96 illustrated. Oxford, London etc.: Pergamon Press. 1965. 50s.

This book is so bad that it has a certain importance. It is an anachronism not only in the sense that at least one of the three drugs it discusses has already been superceded, but because its whole approach to the clinical investigation of new drugs is thirty years out of date. There is scarcely anything in this self-styled symposium which deserves to be called a clinical trial, let alone a controlled trial, and the printed discussion is piffling. The book costs fifty shillings, for less than ninety pages of text with no index, but it would be a waste of money at any price.

Neuroleptanalgesia is a technique of considerable potential value, and the drugs used are of immense interest, but nobody would guess it from this publication. In this respect the manufacturers have been their own worst enemies in sponsoring such an enterprise; yet one wonders just what alternatives were open to them. Many of the difficulties in the current relationship between the drug industry and the medical profession are illustrated by the appearance of a volume of this kind-hence its certain importance.

Drug firms repeatedly affirm that they have no difficulty in obtaining clinical investigators; in a sense this may be true, quantitatively if not qualitatively. It would be unrealistic to imagine that there are not plenty of people in the medical profession, as in every other walk of life, who will readily undertake a task for which some interested party has persuaded them that they are suited. But is not time we stopped paying lip service to the need for good, meaningful, clinical trials and began to set up machinery which would make it possible to undertake them, instead of having to canvass individual doctors and make do with whatever statistical and other "expert" advice happens to be at hand, if any!

The drug industry has large amounts of money available for clinical investigation, and freely admits the fact. Surely some of this money could be pooled 